\title{
SOME EFFECTS OF TEMPERATURE ON THE EMBRYONIC DEVELOPMENT OF THE SALMON (SALMO SALAR)'
}

\author{
By I. R. Hayes², D. P'Elluet ${ }^{3}$, and Evilde Gorha ${ }^{4}$
}

\begin{abstract}
This is a study of the effects of temperature on morphogenesis, and is an attempt to determine whether the order of appearance of anatomical features can be altered within the limits of survival. The time in clays (usually fron closure of the blastopore) for features to appear was noted, and from this the rates were calculated, being the reciprocals of days $\times 10^{3}$. Rate plotted against temperature gives in general a straight line whose slope may be calculated. Some slopes were: hatching, 4.6 ; digestive system, 6.4 ; skeleton, 6.5 ; nervous function, 8.2; external pigment, 9.6 ; blood vessels, 10.0 ; fins, 10.3 ; eve pigment, 12.5. Thus hatching would be expected to appear precociously at low temperatures, and eye pigment at high temperatures.
\end{abstract}

This work constitutes a study of some effects of temperature on the development of the salmon embryo. It is a further investigation along lines begun by Hayes and Pelluet (5), and represents an attempt to determine whether the order of appearance of morphological features during development may be altered by the use of different developmental temperatures within the limits for survival.

\section{Methods}

Salmon eggs were obtained at intervals from the Dominion Government Hatchery at Bedford, N.S. They were established in a small hatchery in the Zoology Laboratory at Dalhousie University. From the university hatchery batches of eggs were transferred for experimental purposes to controlled temperature chambers.

In earlier experiments the chambers were as described by Hayes and Pelluet (5), two methods being used to rear the eggs. In one method 10 eggs were placed in a $2-\mathrm{oz}$. bottle with a thin layer of tap water and an atmosphere of oxygen over then. Ten of these bottles were placed in each chamber. This method was only partially successful, since there was a high mortality just previous to and continuing after, hatching. Up to this point development appeared normal except that in the coldest chambers the embryos sometimes died at an earlier stage. The second procedure was to place a layer of eggs in a glass dish $24 \mathrm{~cm}$. in diameter, filled with tap water plus $10 \%$ Halifax sea water to a depth of $6 \mathrm{~cm}$. The water was then aerated by means of an aquarium pump or by compressed air. With this treatment eggs were hatched and reared to the fry stage, but utilization of all the chambers was not

1 Manuscript received September 2, 1952.

Contribution from the Zoological Laboratory, Dalhousie University, Halifax, N.S., with funancial assistance from the National Research Council and the National Cancer Institute.

2 Professor of Zoology.

3 Associate Professor of Biology.

4 Formerly Graduate Student in Zoology, at present Lecturer in Botany, University College, London, England. 
possible since the air jet interfered with the temperature difference between them. To obtain sufficient data to determine the most suitable graphic plot for the temperature relation, it was necessary to use the first method, and to restrict the experiments to the earlier features of development. The second method served to determine something of the extent and nature of the dissociations throughout the course of development.

For later experiments a refrigerated laboratory was available. Eggs were placed on standard hatchery trays in 8-gal. aquaria and the water was frequently changed. Air was bubbled in to the tanks and a constant temperature was maintained in each by a heater whose setting was adjusted by a variable transformer. Heat was applied continuously and the fluctuation in water temperature was well within one degree. The system was protected by a thermostat designed to turn off all heaters if the room began to warm up. Great care was taken to avoid thermal and mechanical shocks, overcrowding, and oxygen deficiency, and it was anticipated that only a low mortality would occur. In this we were dissappointed because, for reasons not yet clear, no batch of eggs was ever brought through from early stages to completion of yolk sac absorption. We have been unable to find a satisfactory substitute for running water. It is obvious that the account which follows would have been more fully documented if single batches of eggs could have been kept alive for long intervals.

Eggs can be transferred to experimental tanks either in the first two or three days after fertilization, or after the blastopore has closed. Attempts to handle eggs between these dates results in heavy or total mortality.

Examination was carried out with a binocular microscope at intervals of from one to six days, depending on the temperature at which the experiment was being conducted. From 2-10 eggs were looked at in each examination, the capsule being removed in most cases. The yolk sac was left intact at the beginning of the examination but was usually removed later.

Eggs were taken from the University or Bedford hatcheries and placed under different controlled temperatures in nine main experiments, of which the following description of one will serve as an example:- Jan. 28, 1946. Eggs brought from Bedford hatchery and established immediately under 11 temperatures from $1.3^{\circ} \mathrm{C}$. to $14.5^{\circ} \mathrm{C}$. Degree of development approximately that described by Pelluet (12) as stage 6 , vitelline vein prominent with unpigmented blood flowing through it. The eggs were reared in 2-oz. bottles under oxygen, and the number of days to reach various points in development, as marked by the appearance of certain morphological features, was recorded for each temperature. Some of the results are shown in Fig. 1. While errors in observing the number of days for a structure to appear may in some cases be quite considerable, those in determining the order of events are not as great, since it was generally found that embryos at the same temperature showed the same order of events even when the number of days varied. 


\section{Temperature Relations}

The effects of temperature sometimes appear initially as a rate (heart beat, oxygen consumption, etc.) and sometimes as a time (days to hatch and other data in this paper). One kind of measurement is the reciprocal of the other. Thus if, as often happens, a rate curve is approximately a straight line, the corresponding time curve will be a portion of a rectangular hyperbola. We find it more convenient to deal with straight lines than curved lines, and have therefore, by taking their reciprocals, converted the attainment times in this paper into rates. The slope of a rate curve is a measure of the effect of temperature on reaction velocity and permits comparisons to be made between different processes. Table I gives the method used for calculating slopes.

TABLE I

DATA ON THE APPEARANCE OF BLLE IN LUMEN OF GUT AT VARIOUS TEMPERATURT:

\begin{tabular}{|c|c|c|c|c|c|}
\hline & $\begin{array}{c}1 \\
\text { Temp., } \\
\text { degrees } \\
\text { C., } \\
x\end{array}$ & $\begin{array}{l}2 \\
\text { Days for } \\
\text { bile to } \\
\text { appear, } \\
y\end{array}$ & $\begin{array}{c}3 \\
\text { Rate, being } \\
1000 \\
\text { divided } \\
\text { by days, } \\
v\end{array}$ & $\begin{array}{c}4 \\
\text { lemp. } \\
\text { multiplied } \\
\text { by rate. } \\
\text { Col. } 1 \times \\
\text { Col. } 3 \text {, } \\
x v\end{array}$ & $\begin{array}{c}5 \\
\text { Temp. or } \\
\text { Col. } 1 \\
\text { squared, } \\
x^{2}\end{array}$ \\
\hline & $\begin{array}{r}4.8 \\
6.2 \\
8.3 \\
9.8 \\
11.3 \\
12.2 \\
13.1 \\
13.9 \\
14.5\end{array}$ & $\begin{array}{r}40 \\
25 \\
19 \\
13 \\
11 \\
10 \\
8 \\
8 \\
8\end{array}$ & $\begin{array}{r}25 \\
40 \\
53 \\
77 \\
91 \\
100 \\
125 \\
125 \\
125\end{array}$ & $\begin{array}{r}120 \\
248 \\
440 \\
755 \\
1028 \\
1220 \\
1638 \\
1738 \\
1813\end{array}$ & $\begin{array}{r}23 \\
38 \\
69 \\
96 \\
128 \\
149 \\
172 \\
193 \\
210\end{array}$ \\
\hline Sum & 94.1 & & 761 & 9000 & 1078 \\
\hline Mean & $\begin{array}{l}10.5 \\
M_{x}\end{array}$ & & $\begin{array}{c}85 \\
M_{b}\end{array}$ & $\begin{array}{l}1000 \\
M S_{x x^{*}}\end{array}$ & $\begin{array}{l}119 \\
M\left(x^{2}\right)\end{array}$ \\
\hline Mean squared & $\begin{array}{l}109 \\
\left(M_{x}\right)^{2}\end{array}$ & & & & \\
\hline
\end{tabular}

*Illustrated in Fig. 1 on line marked (2). The slope of the rate curve, $k_{1}$, is calculated by the method of least squares, being given by the equation

$$
\begin{aligned}
k_{1} & =\frac{M_{x v}-M_{x} \cdot M_{v}}{M\left(x^{2}\right)-\left(M_{x}\right)^{2}} \\
& =\frac{1000-10.5 \times 85}{119-109}=10.8
\end{aligned}
$$

where the values of the symbols are as indicated in the above table.

Note: Col. 2 is not used in the calculation of slope, being included here merely to exhibit the original data. In this example all the temperatures and rates were used, but for other rates shown in Fig. 1, where lines are inflected to horizonial at higher temperatures, the last points were omitted from the slope calculations. 
The relationship between time and temperature, described in the foregoing paragraph, is known as the rule of thermal summation. The rule states that the time, $y$, to reach any stage of development, multiplied by the temperature, $x$, is a constant, i.e. $y x$ equals $k$. Often another constant has to be added or subtracted from the temperatures before the rule of thermal summation holds. This relation is the same as that which Krogh (8) found applicable to development in a variety of animals (fishes, amphibia, insects, and echinoderms), where the plot of rate versus temperature yielded a straight line.

Fig. 1 gives graphic pictures of the relation between differentiation and temperature. They have been made from the Jan. 28, 1946, experiment described above. Both time and rate plots have been constructed, and from the latter it is clear that the linear rate-temperature relation forms an adequate expression for the data over the greater part of the range.

It is interesting to note the points at which there is an actual divergence from the straight line treatment. That at which the curve for half-vascularization of yolk breaks away is near $9^{\circ} \mathrm{C}$. (No. 5 on graph). Other lines break at

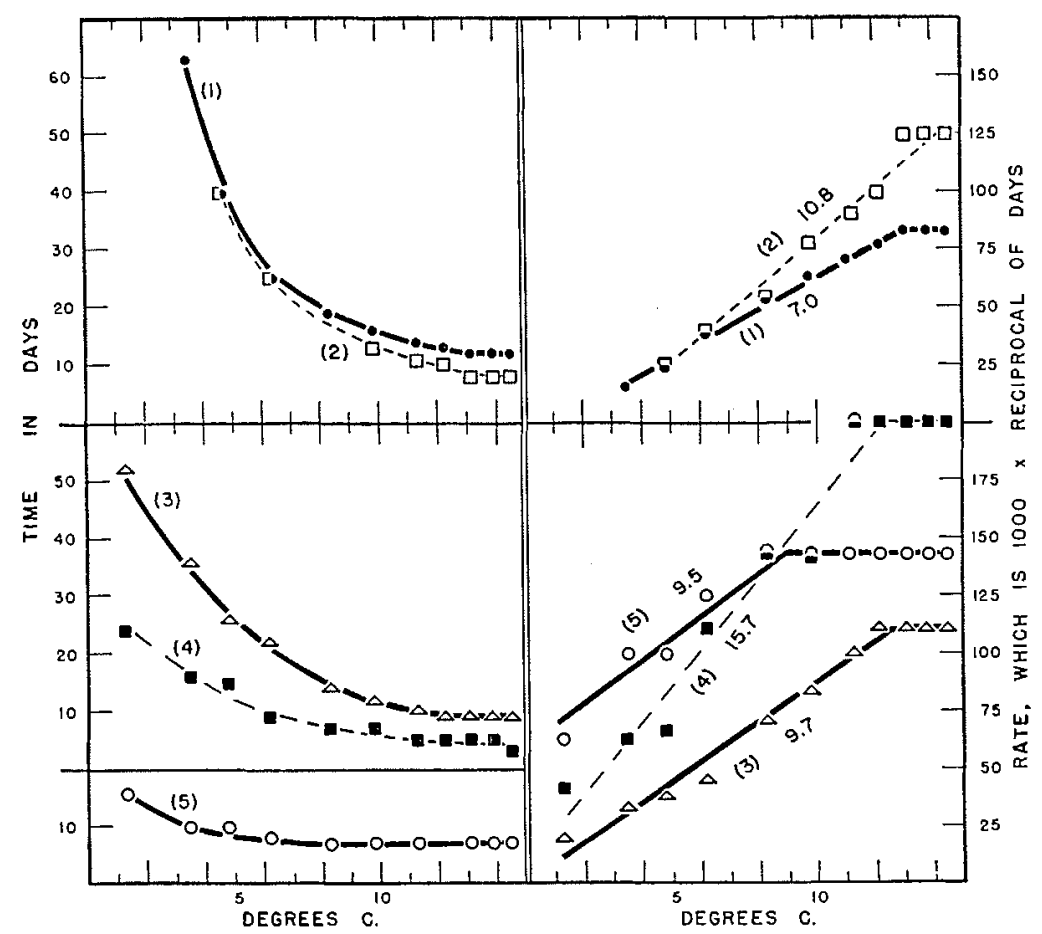

FIG. 1. Effect of temperature on the development of five morphological features. The experiment was started at approximately the time of blastopore closure. Left side of figure is days to attain the feature. The right side is a plot of reciprocals of the days $\times 10^{3}$, which are rates. Numbers beside the lines are slopes of the rate curves. Note that at high temperatures the accelerating effect of heat no longer operates. The point where the rate curve breaks varies from one process to another. The morphological features are identified by numbers as follows: 1. Establishment of tail circulation. 2. Appearance of bile in lumen of gut. 3. Completion of yolk sac circulation. 4. Development of pigment in the eye- 5 . Yolk sac more than half vascularized. 
$11-13^{\circ} \mathrm{C}$. Some rate lines actually cross one another, e.g., 1-2 and 4-5. The slopes of the rate curves, which have been entered on Fig. 1, give quantitative expression to the effect of temperature on the processes described. Measurements on embryonic weight gain or yolk loss, such as those of Hayes and Pelluet (5), can also be fitted quite well by rate curves. Observations covered a 10-day period sometime after hatching, during which a linear relation held, as shown in Fig. 2.

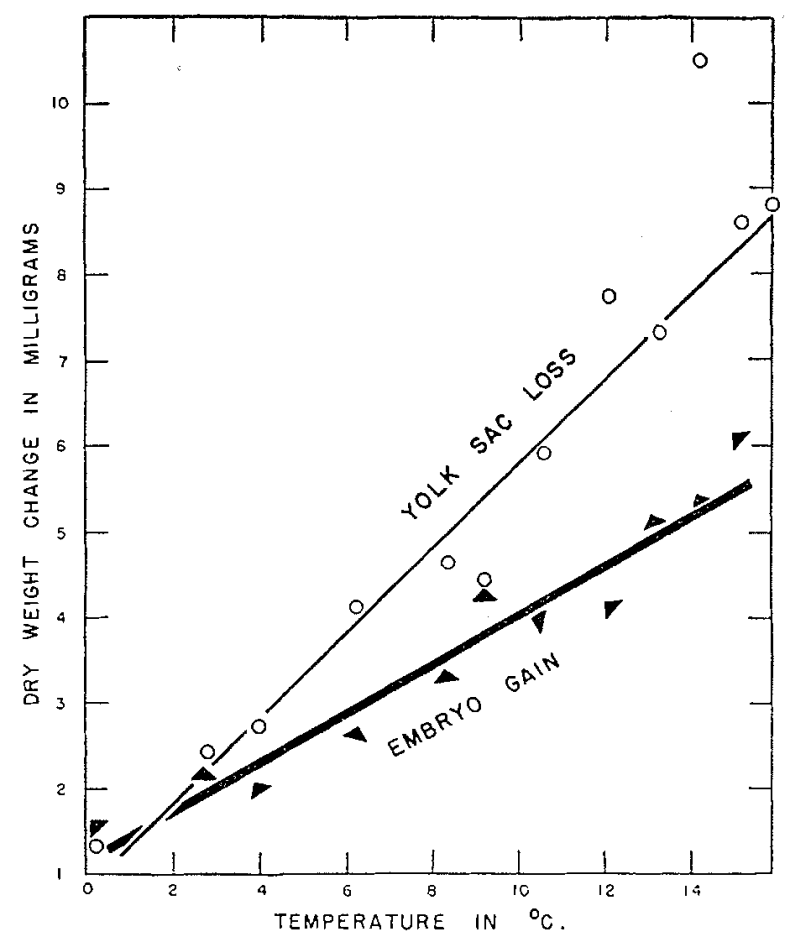

Fig. 2. Yolk loss or embryo gain in dry weight during a 10-day period of the posthatching interval. Eggs were reared in flat-bottomed dishes containing $\frac{1}{2}$ in. of water, and kept in temperature chambers. In this case rate was the effect directly observed and the relation is seen to be linear. Data of Hayes and Pelluet (1945).

In Table II are included the slope constants of various rate curves. These are averages calculated from several series of observations.

\section{Dissociation}

Some indication of a dislocation of differentiation processes in the salmon has been given by previous studies in this laboratory. Hayes (4) suggested that various factors, one of which is temperature, may cause the gland cells producing the hatching enzyme to secrete earlier than usual, and Pelluet (12) found the hatching period to occur rather variably with regard to designated developmental stages. An actual "uncoupling of embryonic processes" was also described by Hayes and Pelluet (5) in a study of temperature effects on 
growth. However, their experiments dealt only with nonappearance of fat in the gut mesentery and failure of the gut to turn, at the warm and cold extremes respectively.

An inspection of Fig. 1 and of 'Table II reveals clearly that differences in the order of appearance of structures (as distinct from a complete inhibition) may be obtained by allowing development to proceed at different temperatures within the limits for survival. Thus at high temperatures the bile became noticeable in the widened lumen of the gut before the completion of the yolk circulation and establishment of blood vessels in the tail. At lower temperatures it slowed down relative to the other two processes, which overtook it. Thus at $3.5^{\circ} \mathrm{C}$. it had not appeared when the period of mortality occulred in this experiment shortly before hatching, although both the other features had been observed. A similar reversal in the appearance of eye pigment and the time at which the yolk sac became half-vascularized may also be observed in Fig. 1. As has been seen, the rate (reciprocal of time for feature to appear) varies for the most part directly with the temperature, and a comparison

TABLE II

EFFECT OF TEMPERATURE ON THE RATISS OI DEVELOPMENTAL PROCESSES. FIGURES GIVEN ARE THE SLOPIS OF RATE CURVES. RATE IS DEFINED AS 1000 TIMES THE RECIPROCAL OF THE

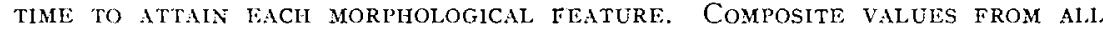
EXPERIMENTS

I. Hatching

II. Differentiation of the digestive system, average Appearance of bile in lumen of gut Formation of stomach

Appearance of folds or coils in intestine Fat seen in mesentery of gut or in spleen

III. Development of the skeleton Cartilage seen in dorsal and anal fins Rays seen in caudal, dorsal, anal, and pectoral lins

IV. Development of nervous function as measured by mobility Beating of pectoral fins Jaws scen to be moving

V. Developnent of external pigment Black chromatophores on head Black chromatophores on various parts of body Red and yellow chromatophores at several places

VI. Developnent of blood vessels Yolk half vascularized Yolk circulation complete Development of capillary system in tail

VII. Appearance of external structures Caudal fin Dorsal fin Pelvic fins

VIII. Black pigment showing in eyes (Development of visual function?)

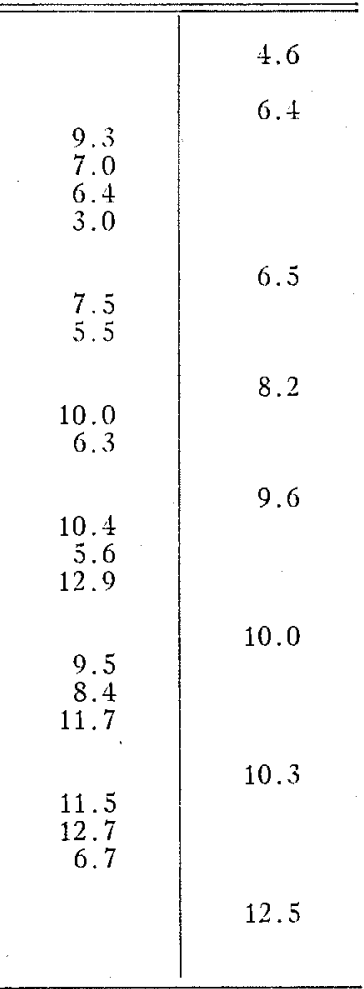


of the slope values of the rate curves for these processes which are presented in Table II, shows that the value for eye pigment exceeds the value for vascularization of the yolk. Since these processes are occurring at approximately the same time, the high value for eye pigment indicates that it is more affected by temperature change than is vascularization of the yolk, being faster at the high and slower at the low temperatures.

We might conclude in a general way from Table II, that low temperatures favor precocious hatching and differentiation of the digestive system and skeleton. On the other hand, high temperatures promote the completion of a functional circulatory system and external features such as fins and pigment. The maximal high temperature effect observed was on eye pigment. Whether this indicates a development of visual function or not is a question. Other evidences of nervous function, such as beating of fins, were intermediate in their response to temperature.

Regarding hatching, it is well-known in hatcheries that a very prolonged cold winter prevents normal hatching although the egg capsules give way and the embryos die while emerging. Normal hatching proceeds by the tail breaking through the capsule first. In cold experiments many embryos were found hatching head first or yolk sac first, with a consequent pinching of the yolk sac and body. They usually died, although in a few instances embryos were observed to hatch head first and survive, and to be developing normally when observed several days later. None was observed to hatch yolk sac first and live.

A rather striking effect of temperature is illustrated in the following example. Pelluet described stage 15 as consisting of $(a)$ the appearance of pyloric caeca, (b) the appearance of black pigment patches on the sides, and (c) a heavy deposition of fat in the gut. In the present study, it was found that at $11.4^{\circ} \mathrm{C}$., the fat and caeca appeared long before the pigment patches, which were observed to be forming at about the time the yolk was completely absorbed. In a later experiment, at $14.1^{\circ} \mathrm{C}$. (started from a later stage), the embryos failed to show any sign of patches before the yolk was absorbed and they died of starvation. In contrast to this, at $6.6^{\circ} \mathrm{C}$. fat appeared first, the pigment patches appeared while the yolk sac was still prominent, and the caeca in the gut did not form until several days later.

Abnormalities are produced by extremes of temperature at many stages in fish development (Stockard (14)) and the effect varies with the stage. When eggs were developed at $11.5^{\circ} \mathrm{C}$. (starting at approximately stage 6 of Pelluet) the hatched embryos showed a marked flexure of the neck and tail over the yolk sac, so that normal swimming movements were impossible. A similar result was obtained by subjecting slightly more developed eggs to a temperature of $15.5^{\circ} \mathrm{C}$. In both these experiments there was a high mortality during and following hatching, but more severe at the higher temperature. However, when eggs of the second lot were kept at $11.5^{\circ} \mathrm{C}$. they survived without a high mortality at hatching. At first a slight flexure was noticed, but later it disappeared. It appears as though at $11.5^{\circ} \mathrm{C}$. the critical period 
is around stage 6 , and the effect is still manifested to a slight degree at a somewhat later period. If this later stage is subjected to an even higher temperature however, the full effect of the abnormality may be restored. Finally, eggs were placed at $14.1^{\circ} \mathrm{C}$. from approximately stage 11 of Pelluet. None of these exhibited any bending of the body after hatching, and developed without great loss to the fry stage; the critical period had been passed. Battle (1), in work on the teleost Enchelyopus, also finds that the degree of abnormality varies with the severity of the treatment. It therefore seems to be an effect on the rate relations of processes rather than an "all or none" phenomenon. Some degree of regulation was evidenced in the second lot at $11.5^{\circ} \mathrm{C}$., since they returned to normal later on. Extreme powers of recovery from temperature-produced abnormalities are recorded for an amphibian (Coghill (3)).

\section{Discussion}

We may conclude from the above experiments that dislocations in the order of differentiation are possible with a change in the temperature at which development takes place, and that certain of these may take place within the normal limits for survival, although in the present study there has not been a survival to the fry stage in every instance.

It is probable that, in the embryo at least, these limits are governed at many stages by the amount of dissociation which can be tolerated between processes fundamental to the well-being of the embryo. Other factors, such as oxygen diffusion (Hayes et al. (6) ) may of course be limiting at some points of development.

Heat death in adult organisms has been held by some workers to be due to protein coagulation or to some effects on the fats or lipids of the cell. Certain objections have been raised to such an hypothesis by Cameron (2), who believes that in highly organized animals the cause of death may be attributed to some change damaging the co-ordinating mechanism. This might in turn be due to a different susceptibility to temperature change in the rates of the various metabolic processes.

The fact that the thermal limits of embryos are generally narrower than those of adults, and may vary from stage to stage (Battle (1).), suggests that effects on the proteins or lipids are not the main factors involved here, although they may appear secondarily. It is more likely that, owing to a differential action on the rates of certain fundamental processes of metabolism, a degree of unbalance is reached at these limits which cannot be tolerated by the embryo. Wood (16) finds that in the trout the relations of the fundamental processes of respiration and growth in weight are unchanged over the temperature range normal to the fish, but that above and below this range respiration increases relative to growth and a smaller embryo results.

This unbalance of rates at the limits of the range may cause the production of monsters before the true lethal limit is reached. Stockard (14), who worked a great deal in this field, believes that unless they are produced by hereditary 
factors, deformities are all caused by temporary inhibition of the rate of development (a "developmental arrest") which deranges the relative gradients of certain processes. The deformity varies with the time of inhibition because of the differences in relative metabolic gradients at the different stages of development.

The dislocations discussed above are also similar to certain dissociations of the major developmental processes of growth, determination, and differentiation reviewed by Needham (11), although his examples have generally been the result of unnatural conditions. The work of Twitty (15) is also relevant. He found by grafting experiments that the polarity of ectodermal ciliary beat in amphibians was normally determined at the closure of the neural folds, but with low temperatures determination took place at a much earlier stage in development.

Additional evidence that there is a differential effect by temperature may be derived from the work of Ljubitzky and Svetlov (10), who observed that succeeding stages in the formation of the pectoral fin in the trout responded differently to temperature. Similar results were subsequently obtained by Ljubitzky (9), for embryo formation in the trout egg.

That the end product of differentiation may be changed with a difference of developmental temperature has been shown by Schmidt (13) and Hubbs (7) in fishes. The latter worker found that in a year class which had developed in a cooler year than usual, the average number of vertebrae, scales along the lateral line, and branched anal rays was increased. This may be construed as supporting the general thesis that temperature affects certain processes differently during development.

The reasons that phenomena similar to those here described have not been apparent in many studies of temperature relations of embryos may be many. Simultaneous features selected as stage markers may be of such fundamental importance to the embryo that any dislocation would result in death, or at least in the production of monstrosities. In this case the temperature coefficients would necessarily be the same. Or features may have been selected which must follow one another, so that their order could not be reversed. Cases of this type are the use of successive stages of cleavage, blastula formation, and gastrulation, and of somite number and embryo lengths. Another is the identification of stages based chiefly on increase of specialization in one particular feature such as the external form of the limb bud. In these cases the temperature coefficients need not correspond. From the results of the present study we may conclude that stages of development drawn up for one temperature may not represent a true relation in all features when the developmental temperature is altered.

\section{Acknowledgment}

Certain of the observations were made by Miss M. L. Smith, to whom the best thanks of the authors are due. 


\section{References}

1. Battle, H. 1. Effects of extreme temperatures and salinities on the development of Enchelyopus cimbrits (L). Contribs. Can. Biol. and Fisheries (n.s.), $5: 109-192$. 1929.

2. Cameron, A. T. Temperature and life and death. Trans. Roy. Soc. Can., V, 24 (Ser. 3) : 53-93. $19,30$.

3. Cogmile, G. E. liffects of chilling on the structure and behaviour of embryos of $A \mathrm{mb} / \mathrm{y}$ stoma punctatum Cope. I'roc. Soc. Exptl. Biol. Mel. 35 : 71-74. 1936.

4. HAYES, F. R. The hatching mechanism of salmon eggs. J. Exptl. Zool, 89: 357-373. $19+2$.

5. HAYLS, F. R. and PELLUET, D. The effect of temperature on the srowth and efficiency of yolk conversion in the salmon embryo. Can. J. Research, 1), 23:7-15. 1945.

6. Hayes, F. R., Whimor, I. R., and Livingstone, D. A. The oxygen consumption of the salmon egg in relation to development and activity. J. Exptl. Zool. 116:377-398. 1951.

7. Hunas, C L. Variations in the number of vertebrae and other meristic characters of fishes correlated with the temperature of water during development. Am. Naturalist, $56: 360-372$. 1922

8. Krogir, A. On the influence of the temperature on the rate of embryonic clevelopment. Z. allyen. Physiol. $16: 163-177.1914$.

9. LjußrtzkY, A. I. Zur Erforschung des Temperatureffelits in der Morphogenese. II. Einfluss der Temperatur auf die Entwicklungsgeschwindigkeit und Wachstun des Embryos von Salmo trutta L. M. fario. Zool. Jahrb. Abt. Allgem. Zool. Physiol. $54: 405-422 . \quad 1035$.

10. LJUBrTzKY, A. I. and SverLov, P. Differentialbeschleunigungen der Entwicklungsstadien der Brustflossen bei der Bachforelle unter Temperatureinwirkung. Biol. Zentr. $54: 195-210.1934$.

11. Nezdram, J. On the dissociability of the fundamental processes in ontogenesis. Biol. Revs., Biol. Proc. Cambridge Phil. Soc. 8 : 180-223. 1933.

12. Pelluet, D. Criteria for the recognition of developmental stages in the salmon (Salmo salar). J. Morphol. 74:395-407. 1944.

13. Schmid, J. Racial studlies in fishes. II. Experimental investigations with Lebistes reticulatus (Peters) Regan. J. Genetics, 8:147-153. 1919.

14. Stockard, C. R. Developmental rate and structural expression: An experimental study of twins, 'clouble monsters' and single deformities, and the interaction among embryonic organs during their origin and development. An. J. Anat. 28: 115-266. 1921.

15. Twitry, V. C. Experimental studies on the ciliary action of amphibian embryos. J. ExptI. Zool. $50: 319-343.1928$.

16. Wood, A. H. The effect of temperature on the growtl and respiration of fish embryos (Salmo fario). J. Exptl. Biol. 9 : 271-276. 1932. 